\title{
Cultivation of Macroscopic Marine Algae
}

\section{A Subcontract Report}

\author{
John H. Ryther \\ University of Florida
}

November 1982

\author{
Prepared Under Subcontract No. XR-9-8133-1 \\ SERI Technical Monitor: Paul Bergeron \\ Solar Energy Research Institute \\ A Division of Midwest Research Institute \\ 1617 Cole Boulevard \\ Golden, Colorado 80401 \\ Prepared for the \\ U.S. Department of Energy \\ Contract No. EG-77-C-01-4042
}


This report is the final report for FY 1982. The work was performed under subcontract to SERI with funds provided by the Biomass Energy Technology Division of the U.S. Department of Energy.

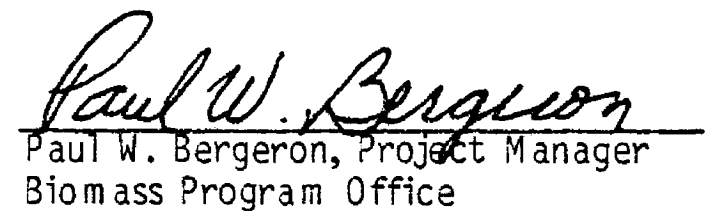




\section{Introduction}

The original concept of an energy farm based upon the production of macroscopic algae (seaweed) was the "open ocean farm," a suspended framework structure buoyed and moored at depths of $700 \mathrm{~m}$ or more in the open ocean to which plants of the giant kelp (Macrocystis pyrifera) would be attached. Nutrient-rich bottom water would be pumped through a pipe to the surface and through the kelp plants as their source of enrichment (Bender, 1980).

Costs of pumping the deep water to the surface and other aspects of the system associated with its deep-sea and open ocean location caused initial doubts concerning its economic feasibility and energy costeffectiveness (Dynatech, 1978; Jones, 1979), and the small test module that was deployed in 1978 was, from the start, beset with numerous technical problems and difficulties and eventually sunk to the bottom without producing useful data.

An alternative ocean energy farm concept that would not be dependent upon deep ocean water or other extraneous sources for its nutrient supply and that could be located in shallow, near-shore, and protected coastal ocean areas has been developed in the course of research on seaweed culture carried out during the past six years at the Harbor Branch Foundation aquaculture facilities in Fort Pierce, Florida. That research will be summarized and the resulting energy farm concept will be described briefly below. 


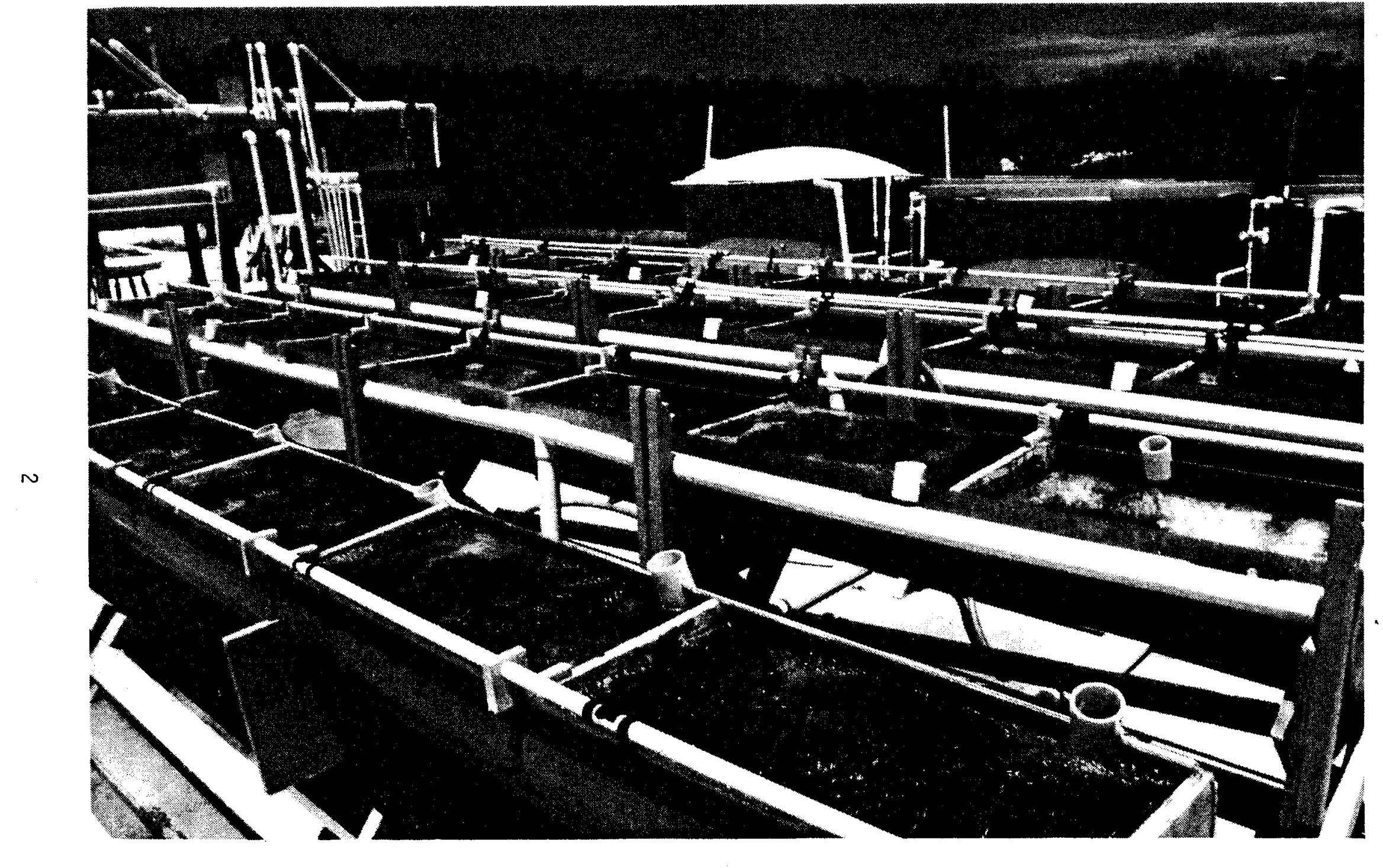

Figure 150 liter seaweed screening tanks 


\section{Initial Research in Florida}

Seaweed production research was initiated with a screening program designed to evaluate growth and biomass production of all macroscopic algal species that could be obtained in adequate quantity in the central Florida area.

The culture system used for the screening was designed and constructed from four 6-m long, 0.4-m diameter PVC pipes that were longitudinally. sectioned and divided into $0.75-\mathrm{m}$ (50 liter) compartments by means of plywood partitions. Each section was provided with a calibrated flow of enriched seawater by means of a manifold fed from a headbox, and also provided with a nonclogging overflow drain. Compressed air was fed into the bottom of each compartment through holes drilled along the bottom of the pipe connecting to an air line (a sectioned one-inch PVC pipe) cemented to the outside of the main pipe. Thirty-two individual growth assay chambers were produced in this way (Figure 1).

The growth chambers were located out-of-doors in full sunlight. Seawater was taken from the Harbor Branch Foundation ship channe1 which connects to the Indian River, a shallow lagoon of the Atlantic Ocean. No attempt was made to control water temperature, which ranged annualiy from $12-34 \mathrm{C}$, or salinity, which ranged from $20-34 \%$, in the incoming seawater. Seawater was pumped into a reservoir tank holding several days' supply for the experimental chambers. Prior to its use, the stored seawater was enriched with the desired concentrations of nitrogen and phosphorus, normally provided as sodium nitrate and 
monosodium (dibasic) phosphate at a ratio of $10: 1$ by atoms of $N: P$, together with chelated iron and a commercial tract metal mixture. Weighed amounts of seaweeds were stocked in the experimental chambers to give the desired density. At intervals of 5-10 days, depending upon growth rate, the algae were removed from the chamber, shaken vigorously to remove water, and weighed. Establishment of the relationship between drained wet weight and dry weight was determined carefully on replicate samples by oven drying at $90^{\circ} \mathrm{C}$ for 48 hours.

A total of 42 species of seaweeds indigenous to the coastal waters of central Florida was assessed this way. That number includes six green algae (Chlorophyta), two brown algae (Phaeophyta), and the remainder red algae (Rhodophyta). The latter group included 11 species or varieties of the large genus Gracilaria, of which over 100 species have been described, as well as the closely related Gracilariopsis sjoestedtii.

Of these, the most successful and suitable species was Gracilaria tikvahiae, formerly G. foliifera var. angustissima (Figure 2). Growth of. G. tikvahiae in the small, intensively operated culture system, with strong aeration and over 20 culture-volume exchanges per day of enriched seawater, resulted in biomass yields throughout the year that averaged $34.8 \mathrm{~g}$ dry $\mathrm{wt} / \mathrm{m}^{2} \cdot$ day (equivalent to 127 dry metric tons/hectare $\cdot y e a r$, about half of which is organic) (Lapointe and Ryther, 1978). Yields were found to be directly proportional to seawater exchange rate, between one and 30 culture volumes/day, for reasons that will be discussed later. Maximum yields occur at relatively low nutrient concentrations, $10-100$ umoles $\mathrm{N} / 1$ as $\mathrm{NO}_{3}^{-}$or $\mathrm{NH}_{4}^{+}$ 


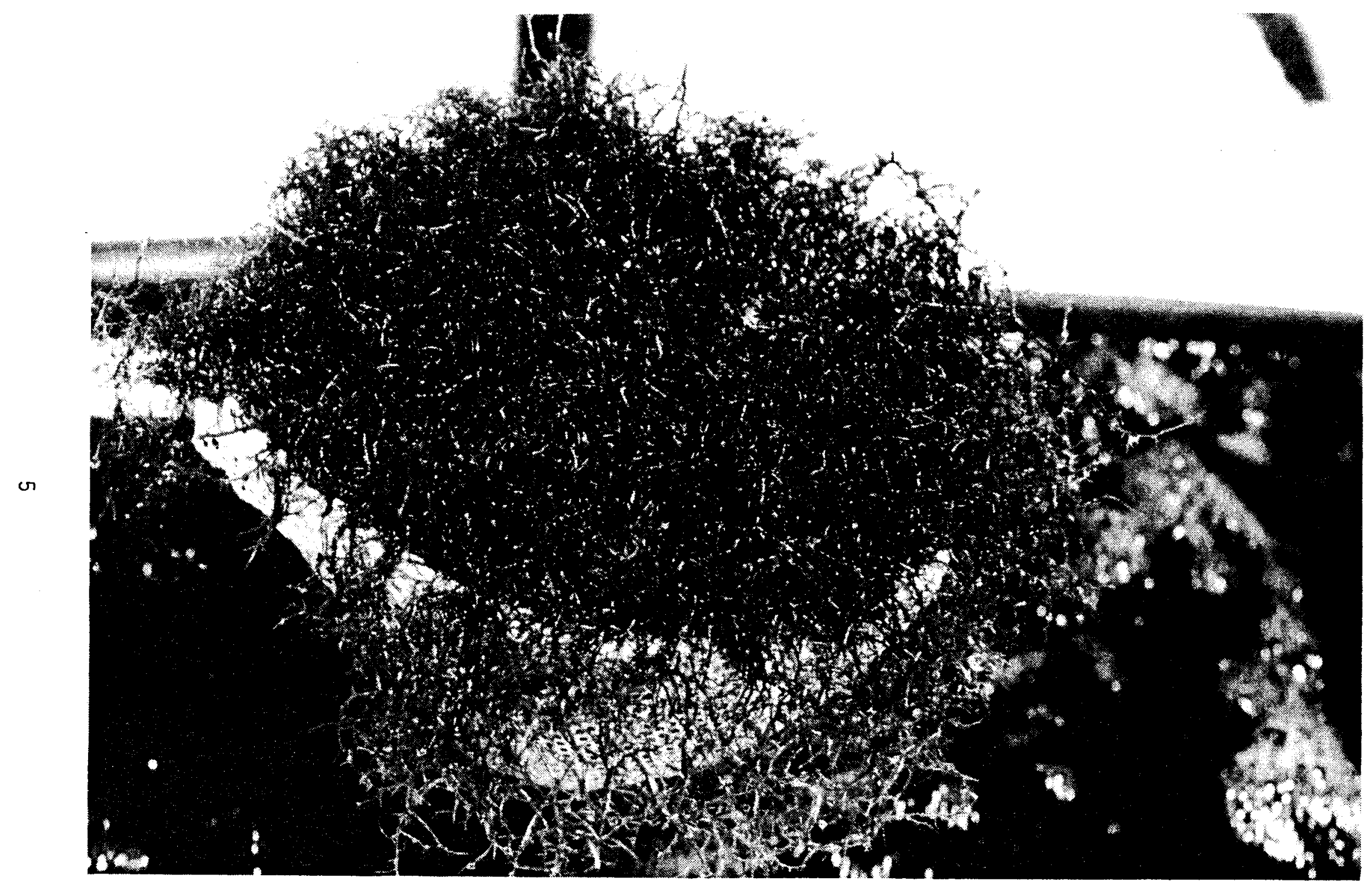

Figure 2 The sterile clone of Gracilaria tikvahiae 
and 1-10 umoles/1 $\mathrm{PO}_{4}=\mathrm{P}$ together with essential trace metals, and a starting seaweed density of $2-4 \mathrm{~kg}$ wet $\mathrm{wt} / \mathrm{m}^{2}$ culture surface area, harvested back to that density every one to two weeks. Growth of Gracilaria occurred throughout the year at Fort Pierce, Florida, with a maximum mean weekly yield of $46 \mathrm{~g}$ dry $\mathrm{wt} / \mathrm{m}^{2} \cdot$ day at the end of July and a minimum of $12 \mathrm{~g} / \mathrm{m}^{2} \cdot$ day in Tate January, when water temperature in the culture fell to $12^{\circ} \mathrm{C}$.

One important advantage of Gracilaria is that the drifting nonattached form is usually sterile and will apparently grow vegetatively indefinitely without the development of a fruiting stage and the cessation of growth that normally accompanies such reproductive activity. Since the initial screening tests in 1976-77, a single clone of $\underline{G}$. tikvahiae has now been grown in culture at the Harbor Branch Foundation continuously for nearly six years.

Highly intensive seaweed culture methods that require large volumes of pumped water and air are probably not economically viable, no matter how high the yields (e.g., Huguenin, 1976). Attempts were therefore made to grow Gracilaria using less energy-intensive culture methods.

Effects of Aeration:

Gracilaria is routinely maintained in suspended culture by aeration along the long axis of the culture tank bottom. What purpose this serves is not known, but apparently does not derive from the air itself, since the same growth enhancement is obtained from seaweed kept in suspension by the action of a paddle wheel (Neish et al, 1977). It may expose a 1 arger density of seaweed to sunlight than would be possible in an unmixed culture, or it may increase the exposure of the plants to $\mathrm{CO}_{2}$ and/or other nutrients. Whatever the function, aeration is a major cost and energy input that should be reduced to a minimum level consistent with high yield. Table 1 
Table 1. Effect of aeration on yield of Gracilaria grown at two retention times of enriched flowing seawater (Mean yields 4/9-5/4/81 in $g$ dry $w t / m^{2} \cdot$ day).

\begin{tabular}{llc}
$\begin{array}{l}\text { AERATION } \\
\text { (hours/day) }\end{array}$ & $\begin{array}{c}\text { RETENTION (days) } \\
0.1\end{array}$ & 1.0 \\
\hline 0 & 18.6 & 8.5 \\
$2(5 \mathrm{~min} / \mathrm{hr})$ & 23.0 & 9.9 \\
$6(15 \mathrm{~min} / \mathrm{hr})$ & 32.9 & 12.5 \\
$6(2 \mathrm{hrs}, 3 \times /$ day, daylight) & 34.0 & 14.2 \\
$12($ daylight $)$ & 36.5 & 14.7 \\
24 & 37.3 & 14.7
\end{tabular}


shows that intermittent aeration, for as little as six hours per day, under two different periodicities, results in the same yields of Gracilaria as does continuous aeration, but that yields decreased in cultures aerated for oniy 5 minutes per hour for a total of two hours per day. The effect of aeration periods intermediate between two and six hours per day and during daylight hours only remain to be investigated.

\section{Nutrient uptake and storage:}

One of the major problems and economic costs of a large-scale seaweed biomass system would be the supply and deployment of essential nutrients to the individual plants and the retention of the enriched water within the area of cultivation long enough for the nutrients to be assimilated by the seaweeds. As mentioned earlier, both the supply and distribution of nutrient-rich deep water were major, unresolved technical and economic problems in the open-ocean farm concept. And the problem is further exacerbated by the need to rapidly exchange the seawater in the culture system, needed to achieve high yields of the seaweeds, as seen above. The provision of just the proper amount at the optimum concentration of each nutrient to each plant under the varying conditions of incident solar radiation, shading, and subsequent assimilation rates by the different plants in the system throughout the day, would seem impossible to achieve without either starvation or excessive wastage.

However, nutrient-deficient seaweed is capable of rapidiy assimilating and storing inorganic nutrients which may then be drawn upon for normal growth for periods of days to weeks in the virtual absence of an external nutrient suppiy. Chapman and Craigie (1977) have described how this system may operate in nature, and D'ETia and DeBoer (1978) have demonstrated, in a controlled experiment, the extremely high affinity for ammonia of nitrogen-starved Gracilaria, far exceeding anything that could be associated 
with uptake kinetics for growth.

The phenomenon of rapid nutrient uptake and storage by starved Gracilaria and its relationship to subsequent growth of the seaweed was studied further (Ryther et al, 1981).

G. tikvahiae was grown for 2-4 weeks in running, unenriched seawater (one volume exchange of water per day) until the algae were a pale yellow color and growth had ceased. Five kilograms (wet weight) were then placed in tanks of seawater enriched with $\mathrm{NH}_{4} \mathrm{Cl}$ and $\mathrm{Na}_{3} \mathrm{PO}_{4} \cdot 12 \mathrm{H}_{2} \mathrm{O}$ to provide 2000 umoles $N$ and 150 umoles $P / l i t e r$. The water was gently aerated to provide motion of the water through the seaweed. Water samples were then withdrawn at intervais and analyzed for ammonium-nitrogen and phosphate-P. In one experiment, $\mathrm{KaNO}_{3}$ was used in place of $\mathrm{NH}_{4} \mathrm{Cl}$.

In one control experiment, no seaweed was added to check any loss of $\mathrm{NH}_{3}$ to the atmosphere during the course of the enrichment. In another control, recently enriched, dark reddish-brown Gracilaria was used to measure uptake rates in non-nitrogen-deficient seaweed.

Samples of the seaweed were taken at the beginning and end of the enrichment period, usually 24 hours, and in one case midway through the experiment. These were oven dried at $80^{\circ} \mathrm{C}$ for 24 hours and analyzed for total $C$ and $N$ with a Perkin-Elmer Model 240 elemental analyzer.

No measurable amount of ammonia was lost to the atmosphere from the tank without seaweed (Figure $3 \mathrm{~A}$ ). Thus any loss from the tanks containing the algae could be assumed to have been due to assimilation by the plants.

There was also no significant removal of nitrogen from the tank containing the well-nourished Gracilaria and held under the same conditions (Figure 3B). However, the ammonia-nitrogen in the tank stocked with $\mathrm{N}$ starved seaweed decreased rapidly, from 16.8 to $3.0 \mathrm{mg} \mathrm{N} / 1$ in just eight hours, to nearly immeasurable levels in 24 hours (Figure $3 C$ ). That loss 


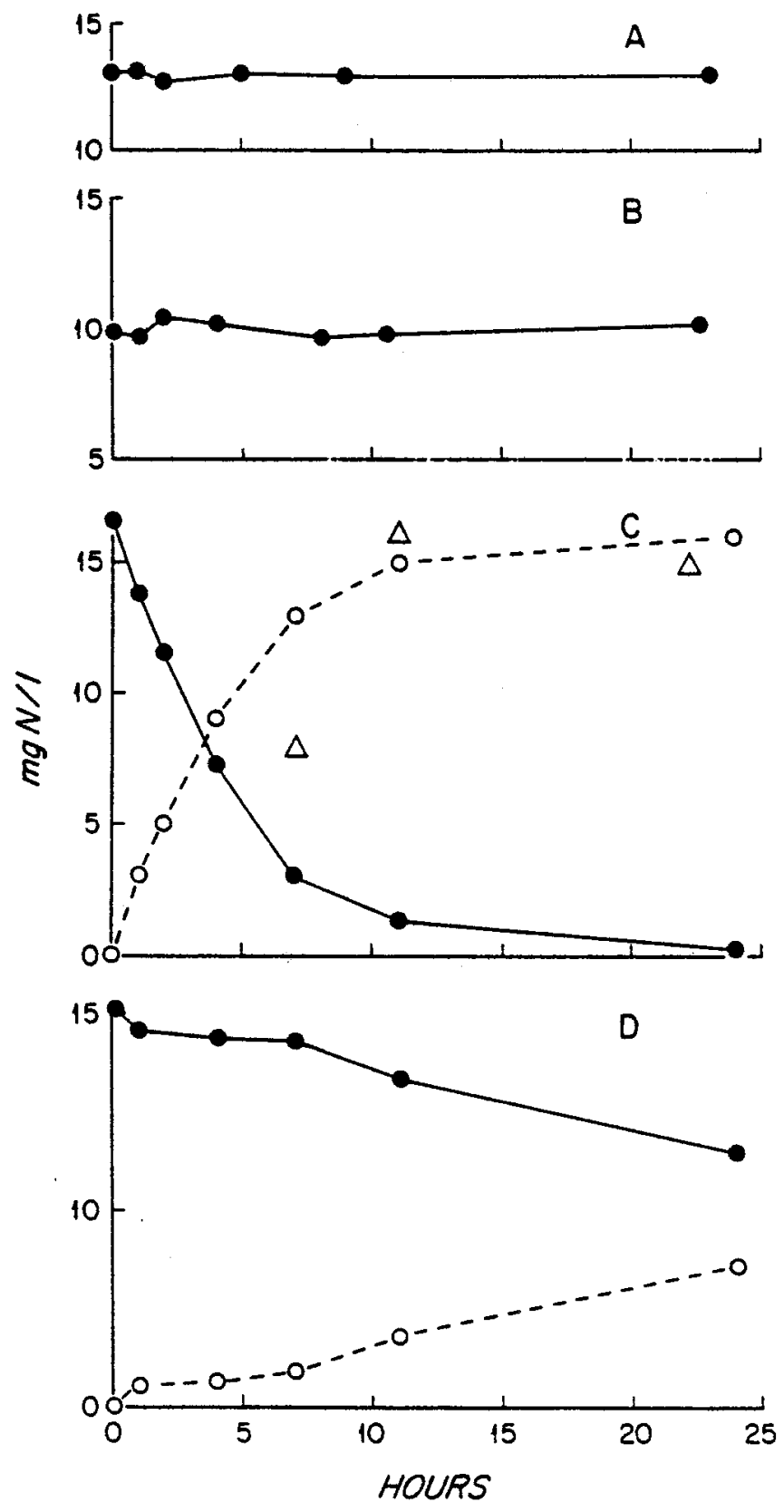

Figure 3 (A) Change in ammonium-nitrogen in tank containing no seaweed.

(B) Change in ammonium-nitrogen in tank containing nọ-nitrogenstarved Gracilaria.

(C) Removal of ammonium-nitrogen from water (solid circles) and calculated uptake (open circles) by nitrogen-starved Gracilaria. Triangles are measured increases in tissue nitrogen by the same plant.

(D) Removal of nitrate-nitrogen from the water (solid circles) and calculated uptake (open circles) by nitrogen-starved Gracilaria. 
represents a total uptake of some $8.4 \mathrm{gN}$ by the $5 \mathrm{~kg}$ wet wt $(0.55 \mathrm{~kg}$ dry wt) of seaweed in 24 hours, a nitrogen increase of $1.5 \%$ of total dry weight or a 2.5-fold increase over the starting concentration of $1.0 \%$ of dry weight. The total measured increase in the plant tissues, sampled at 7,11 , and 24 hours (triangles in Figure $3 \mathrm{C}$ ) agreed well with the increase calculated from the loss from the water (solid circles, broken line, Figure $3 C$ ), confirming the fact that the loss from the water was indeed due to assimilation by the plants.

The experiment in which nitrogen was supplied at the same concentration as $\mathrm{NaNO}_{3}$ showed a much slower rate of uptake by the Gracilaria (Figure 3D). In that case, only $37 \%$ of the available nitrate-nitrogen was taken up, a total of $2.7 \mathrm{~g}$ by the $5 \mathrm{~kg}$ wet wt or an increase of only $0.4 \%$ of the dry weight (e.g., from 1.0 to 1.4 of total dry weight).

In another series of experiments, the long-term effects of rapid nutrient uptake and storage on growth of the seaweed was examined. Two-and-a-half kg (wet wt) portions of yellow, nitrogen-deficient Gracilaria were placed in $2500 \&$ aluminum tanks in seawater enriched with $\mathrm{NH}_{4} \mathrm{Cl}$ or $\mathrm{NaNO}_{3}(1000$ umoles $\mathrm{N} / 1)$, $\mathrm{Na}_{3} \mathrm{PO}_{4} \cdot 12 \mathrm{H}_{2} \mathrm{O}(100 \mu$ moles $\mathrm{P} / 1)$ and a mixture of trace metals and chelated iron. The tank was gently aerated to provide movement of the enriched seawater through the seaweed. The seaweed was held in the tank for various periods of time, from one to 48 hours, after which it was washed in clean seawater and placed in 700 \& concrete tanks, where it was grown in running, nonenriched seawater (one exchange per day), maintained in suspension by vigorous aeration. The experiment was run for eight weeks during which the seaweed was taken from the tanks every two weeks, drained of excess water, weighed and harvested back to its starting weight $(2.5 \mathrm{~kg}$ wet wt). The latter was then put into the enrichment tank again for the same length of time at each biweekly interval. A control was grown in the same manner but 


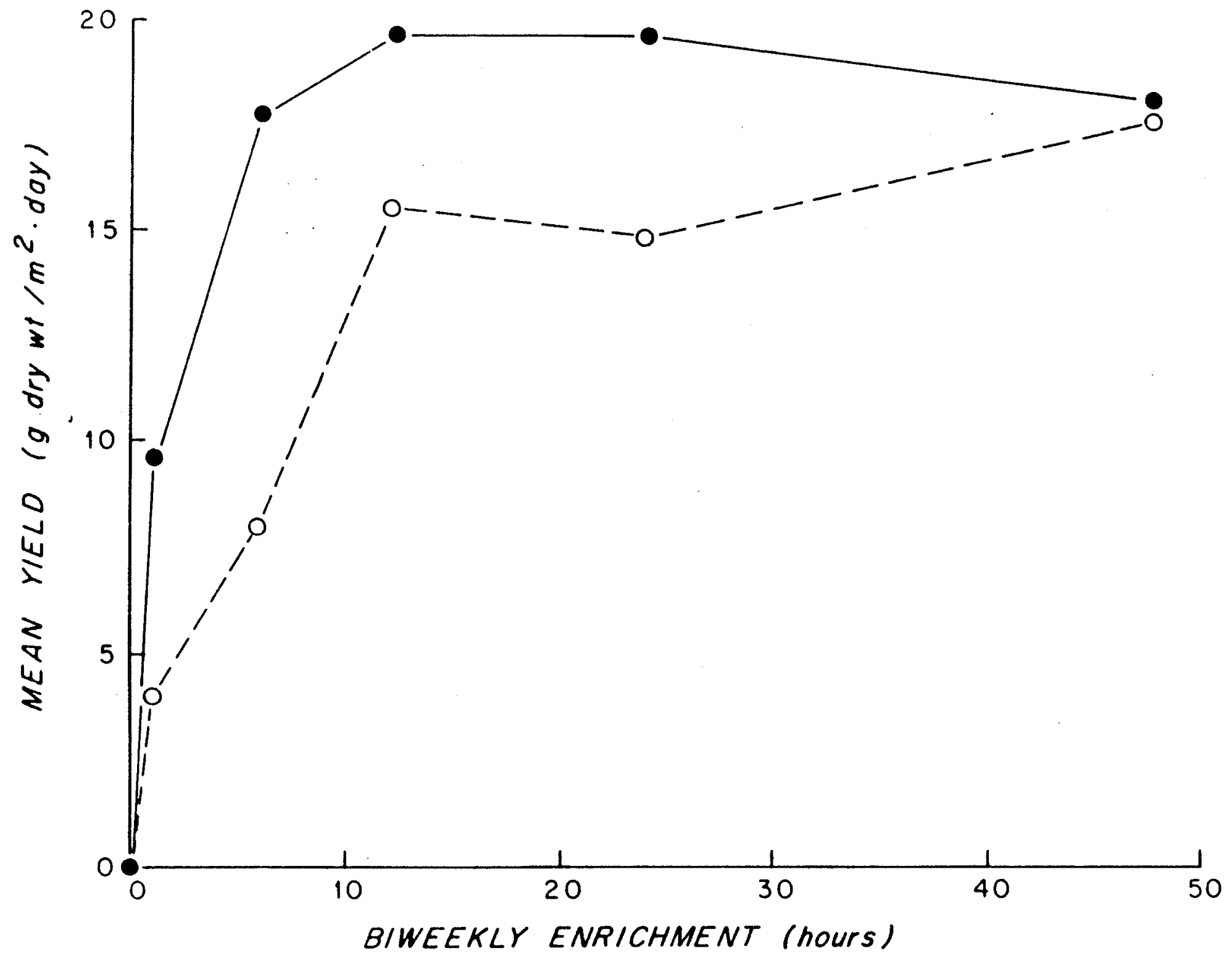

Figure 4 Mean yield of nitrogen-starved Gracilaria immersed in nutrient medium containing ammonium-nitrogen (closed circles) and nitrate-nitrogen (open circles) every two weeks for the periods of time indicated. 
received no enrichment.

The results of this experiment showed that soaking Gracilaria in nutrient-enriched seawater for as little as six hours every two weeks is sufficient to enable the plants to grow at the maximum possible rate under the conditions of the experiment (Figure 4). Increasing the exposure to the nutrients beyond the six hours, to a maximum of 48 hours, had no additional stimulatory effect. Reducing the exposure to one hour resulted in roughly half the yield of seaweed and the control showed no growth.

A companion experiment, in which nitrate rather than ammonium was the nitrogen source, showed a similar but less striking effect (Figure 4). Yields of Gracilaria soaked in the nitrate-enriched medium for durations from one to 24 hours were consistently lower than those exposed to ammonium. Not until the nitrate-soaked plants were exposed for 48 hours were their subsequent yields comparable to those obtained from the ammonium treatment for the same period of time.

The continuous feeding of seaweeds grown in culture by enriching the seawater that flows through the plants is costly and inefficient. Plans to grow the giant kelp (Macrosystis pyrifera) in nutrient-rich deep ocean water, pumped up and dispersed through the kelp beds, appear at best to be marginally feasible economically, due largely to the projected high cost of pumping the deep water to the surface and spreading it through the seaweed. Utilization of the nutrients in that system was estimated at no better than 30\% (Dynatech, 1978).

The smaller, unattached seaweeds like Gracilaria, Chondrus, and other red algae, on the other hand, may be removed from their culture system and soaked in a concentrated nutrient solution for only a few hours during which they are capable of more than doubling their nitrogen content. They may then be returned to the culture system where they will grow with no 
additional nutrients added to the water until they double their biomass, thereby halving their nitrogen content again. Harvesting the new growth may then be accompanied by another session of nutrient-soaking of the standing stock to be returned again to the culture unit.

Not only is such a system highly efficient in nutrient utilization, with no loss of unused nutrients, but it also solves simultaneously one of the chronic problems in seaweed culture, the growth of undesirable epiphytes on the cultured seaweeds. With no nutrients added to the seawater in which the algae are grown, epiphytes do not have an opportunity to become established and the externally-fed target species has the competitive advantage.

Seawater retention, $\mathrm{pH}$, and carbon dioxide:

The one factor that has been found to date the most important in affecting the growth and yield of Gracilaria is seawater exchange rate (retention time). The reason is not obvious, but does not appear to be related to the mineral nutrient supply, since the effect is observed when nutrients are added at a constant rate separately from the seawater supply, or when nutrients are premixed and added at a constant concentration in the seawater supply, or when nutrients are supplied by soaking the seaweed periodicaliy for a few hours in a static, enriched seawater reservoir, as discussed above. Figure 5 is a summary of experiments showing the relationship between yield and retention time, including cultures ranging in size from 50 to 600,000 liters and with both continuously-enriched and pulse-fed cuitures.

Since pumping water is a (probably the) major cost factor in the culture system that is described here, clearly, it would be desirable to achieve the high yields possible at very rapid exchange rates with much less water flow. First, however, it is necessary to understand the relationship 


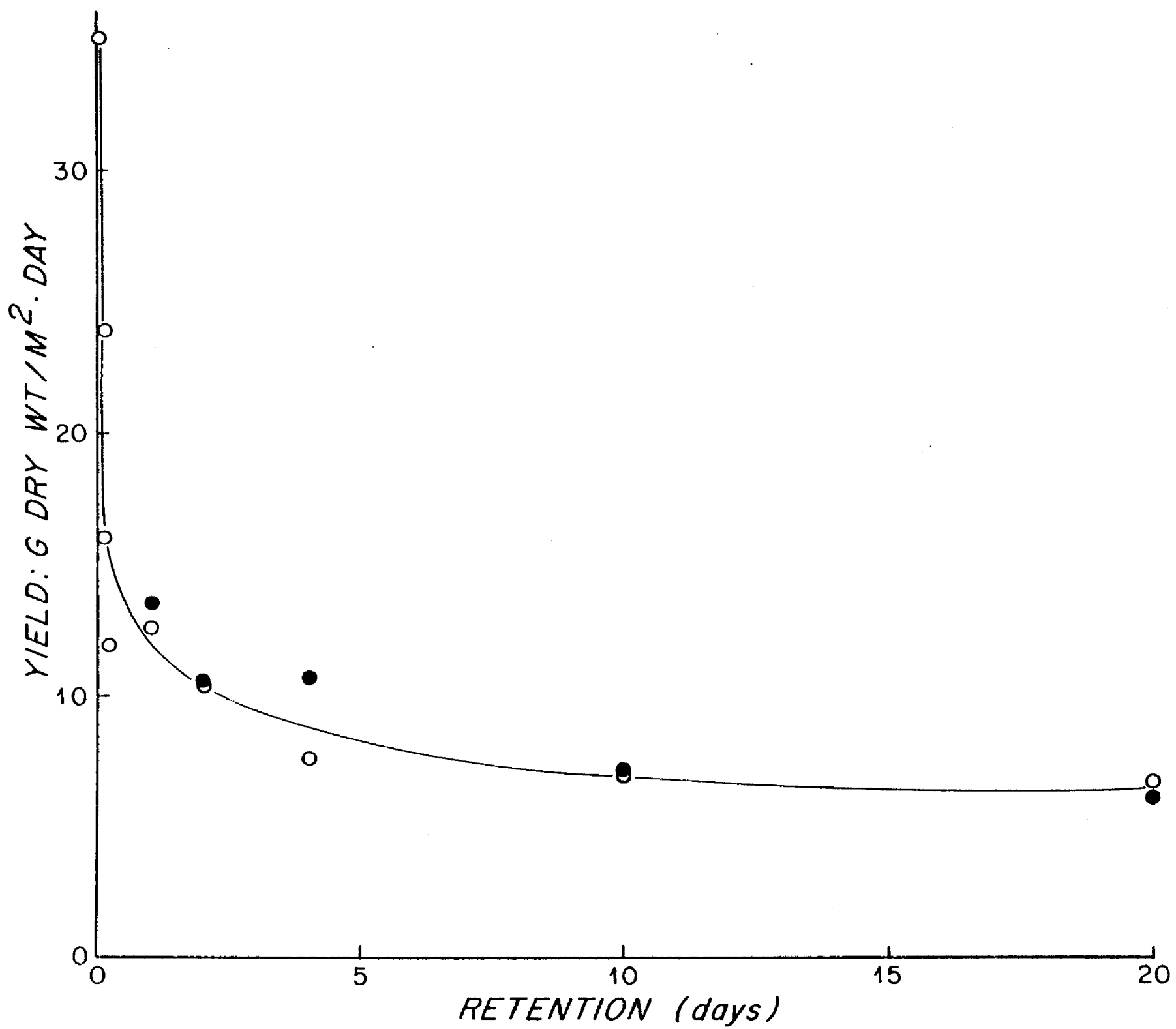

Fiaure 5 Yields of Gracilaria as a function of seawater retention time. Open circles = continuous enrichment; closed circles = pulsed nutrients for 24 hours every two weeks. 
between yield and water exchange.

The only essential nutrient not provided in the artificial enrichment normally used to culture Gracilaria and other seaweeds is carbon dioxide. Seawater of normal salinity (30-35\%) contains about $2 \mathrm{~m}$ moles/liter of total $\mathrm{CO}_{2}$ which exists in the equilibrium:

$$
\mathrm{CO}_{2} \text { (diss.) } \leftrightharpoons \mathrm{H}_{2} \mathrm{CO}_{3} \rightleftharpoons \mathrm{HCO}_{3}^{-} \leftrightharpoons \mathrm{CO}_{3}^{-}
$$

Seawater one-meter deep thus contains $24 \mathrm{~g} \mathrm{C} / \mathrm{m}^{2}$ which could theoretically support the growth of $48 \mathrm{~g}$ ash-free dry weight (50\% carbon) or about $74 \mathrm{~g}$ total dry weight of Gracilaria, a potential yield of $74 \mathrm{~g} \mathrm{dry} \mathrm{wt} / \mathrm{m}^{2} \cdot$ day with a retention time of one day. However, removal of free $\mathrm{CO}_{2}$ during the photosynthetic growth of algae increases the pH; the slower the circulation of seawater through the seaweed the higher the pH rises (Table 2). At $\mathrm{pH}>9.0$, there is almost no free $\mathrm{CO}_{2}$ in seawater (Harvey, 1960) and its rate of dehydration from bicarbonate to maintain the equilibrium is so slow that it may become limiting to photosynthes is and growth.

Some seaweeds are able to utilize bicarbonate directly in photosynthesis. Measurement of photosynthesis $\left(\mathrm{SO}_{2}\right.$ by oxygen probe in a closed, recirculating seawater chamber) at four $\mathrm{pH}$ levels maintained with TRIS buffer indicates, however, that Gracilaria can use little or no bicarbonate, with photosynthesis at pH 9.0 only $19 \%$ of that at pH 7.5 (Table 3 ).

This, then, would account for the poor growth of Gracilaria at low seawater exchange rates and at the accompanying high $\mathrm{pH}$ levels. Other species of seaweed apparently do utilize bicarbonate readily for they continue photosynthes is and growth at high pH. The green alga Ulva lactuca was found to produce oxygen at $\mathrm{pH} 9.1$ at $72 \%$ the rate at $\mathrm{pH} 7.5$ (vs. 19\% for Gracilaria) (Table 3 ). This basic but variable characteristic of seaweeds may be an important criterion for the selection of candidate species for marine biomass production, if the systems used for such purposes are to 
Table 2. Mean, Daytime pH in Gracilaria cultures at different retention times.

\begin{tabular}{lll}
\hline TIME & $\begin{array}{l}\text { RETENTION (days) } \\
0.1\end{array}$ & 1.0 \\
\hline 0800 & 8.2 & 8.1 \\
1030 & 8.4 & 8.6 \\
1315 & 8.7 & 9.0 \\
1435 & 8.7 & 9.1 \\
1530 & 8.8 & 9.1 \\
1615 & 8.7 & 9.1
\end{tabular}


Table 3. Effect of pH on photosynthesis of Gracilaria and UIva, measured by oxygen increase after one hour. Figures are relative to increase at $\mathrm{pH} 7.5$.

\begin{tabular}{ccc}
\hline $\mathrm{PH}$ & Gracilaria & UTva \\
\hline $7.5-7.6$ & 100 & 100 \\
$8.0-8.2$ & 74 & 104 \\
8.6 & 46 & 92 \\
$9.0-9.1$ & 19 & 92
\end{tabular}


consist of extensive marine farms of high growth rate, high yield algal crops maintained in seawater that, for logistic or economic reasons, cannot be rapidiy exchanged.

The above observations on bicarbonate utilization by Gracilaria and Ulva are not original to the present author. Almost exactly the same results with both species were reported by Blinks (1963), who also described similar experiments with 22 other species of seaweeds. A complete spectrum was found in the ability of the different species to photosynthesize at high $\mathrm{pH}$, a phenomenon that Blinks also attributed to the relative ability of the various algae to utilize bicarbonate, as have others (e.g., Osterlind, 1951; Jolliffe and Tregunna, 1970).

However, the reason why algae differ in this respect is not clear and may not even involve bicarbonate utilization (e.g., Goldman et al, 1981). Whatever the explanation, it is tempting to believe that it may be associated with the surface:volume ratio of the seaweeds, which is important in many aspects of their nutrition (Odum et al, 1958, Littler, 1980) and which is strikingly different in Gracilaria $(s: v=30)$ and Ulva $(s: v=165)$ (Rosenberg and Ramus, 1982).

Ulva would be an ideal candidate for marine biomass production for that reason and because of its high inherent growth rate and potential yield, were it not for the fact that the alga normaliy becomes reproductive and sheds a large fraction of its biomass as microscopic gametes or zoospores as often as once a week when it is growing rapidly. Dr. Howard Levine (U. Mass.) kindly provided the author with a sample of UIva lactuca from a population which he had never observed to become reproductive or to bear fruiting bodies. In the year since it has been grown in our culture system, it has also remained sterile, in contrast to several other strains of the same species grown under the same conditions. A permanently sterife clone of UTva, as may now be available, may represent an important contribution 
to the marine biomass field.

Recycling of digester residue as a nutrient source for seaweed production:

While separate pulse feeding of seaweeds, as described in a previous section, has obvious economic advantages over continuous enrichment of the seawater flowing through the cultures, an enrichment medium made from commercial fertilizers or bulk inorganic chemicals still represents a major cost to the production system. However, where seaweeds are digested anaerobically to produce methane, all of the essential nutrients remain in the digester residue or effluent and represent a potential enrichment medium that could be supplied to the production system at little or no cost.

An experiment is currently in progress in which the growth of Gracilaria tikvahiae and UTva sp. are being compared in standard inorganic nutrient medium and in the residue from their own anaerobic digestion as respective enrichment media. Both species are being grown in suspended culture in 2400 \& aluminum tanks (Figure 6).

One of each species is enriched each week, using the pulse-feeding method described above, in an inorganic nutrient solution. The other two cultures are similarly enriched with the liquid residue from an anaerobic digester that is fed weekly the incremental growth of that culture.

Two $20 \&$ carboys are being used as digesters. These were initially inoculated with $11.25 \mathrm{~kg}$ of seaweed, 11.25 \& seawater, and one liter of liquid residue from another seaweed digester. They were run for three weeks in a batch mode with almost daily $\mathrm{NaOH}$ titration in an effort to stabilize $\mathrm{pH}$ to near 7.0. When the latter was accomplished, the digesters were fed weekly, a corresponding amount of liquid residue being withdrawn for the seaweed enrichment.

Growth of Ulva in both media declined from the outset of the experiment, due to increasing summer temperatures that eventually proved lethal to the 


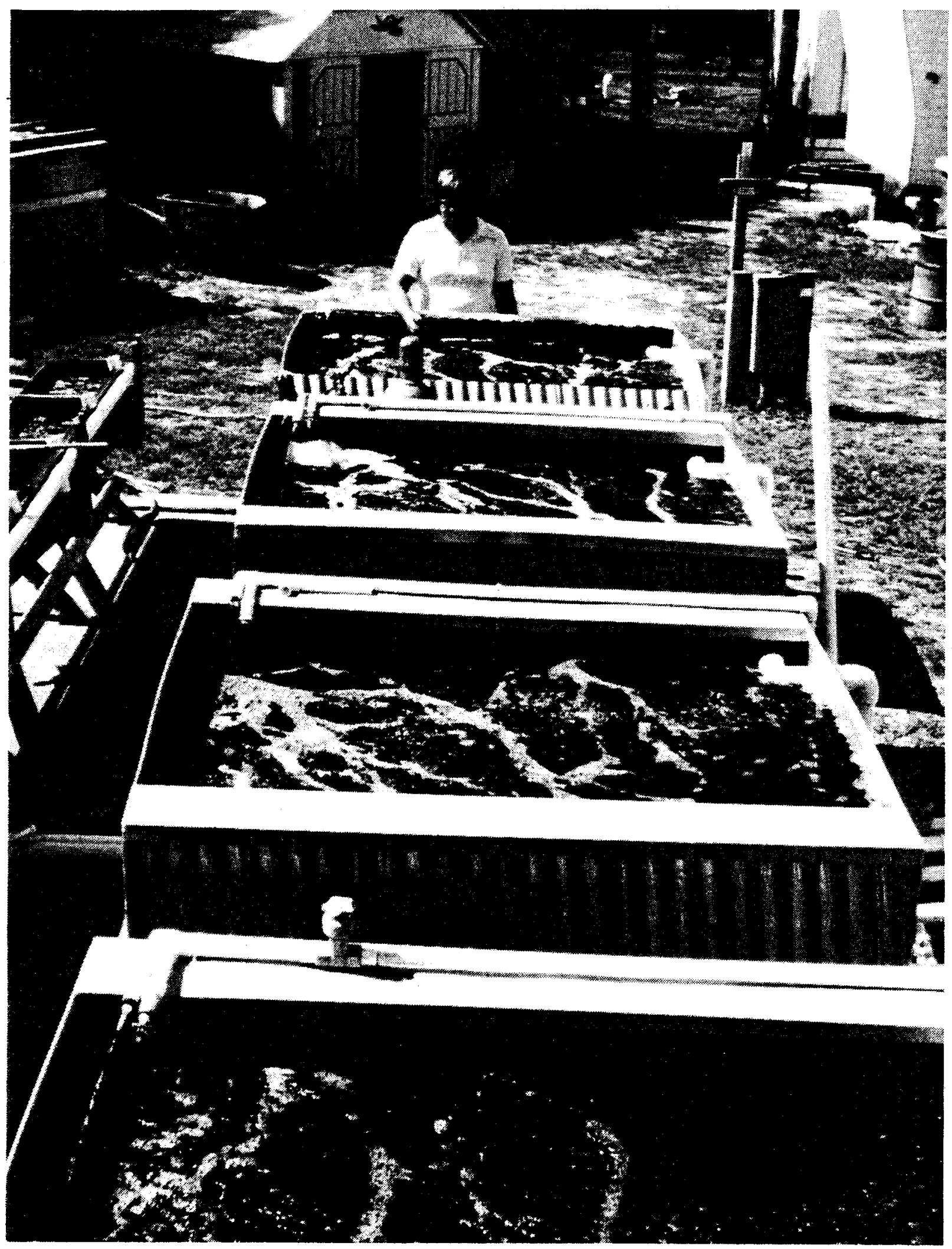

Figure 6 2400-liter aluminum culture tanks used for nutrient recycling experiments. 
species by mid-July. The culture has since been restarted, but new data were not yet available at the time of this writing (October 1).

Figure 7 shows the growth of Ulva and Gracilaria grown in the conventional mineral enrichment medium and in the liquid residue from anaerobic digesters fed the weekiy harvest from each culture. Yields of UTva in both media declined throughout the seven-week experiment as its lethal temperature was approached, but note that growth in the digester residue was generally equal to or better than that in the control inorganic medium. Such was not the case with Gracilaria, growth of which in the recycled nutrients was on7y $50-75 \%$ that in the control. Presumably this reflects the fact that Gracilaria is more resistant to digestion than Ulva, probably because of its agar content which, our earlier studies showed, is initially resistant to decomposition. This means that Gracilaria requires a longer residence time in the digester or some other pretreatment of its residue prior to use as a nutrient source.

Figure 8 , from the same experiment, shows the energy produced as methane per square meter per day from the two residue-fed cultures. Note that although the yields of UIva were on average lower than those of Gracilaria, particularly during the latter part of the experiment when Ulva was losing its fight against high temperatures, the energy yield of Ulva was greater, due to its greater digestability. The latter has been documented el sewhere (Habig and Ryther, in press; Habig et al, unpubl. ms.) and is not reported here, but it is perhaps worth mentioning that Ulva is a particularly good substrate for methanogenesis, presumably because of its high soluble carbohydrate levels, low fiber, and large surface:volume ratio. Its more rapid and more complete digestion is undoubtedly responsible for the more rapid and complete remineralization of its nutrients and their greater availability to the alga as its nutrient source. This is another reason 


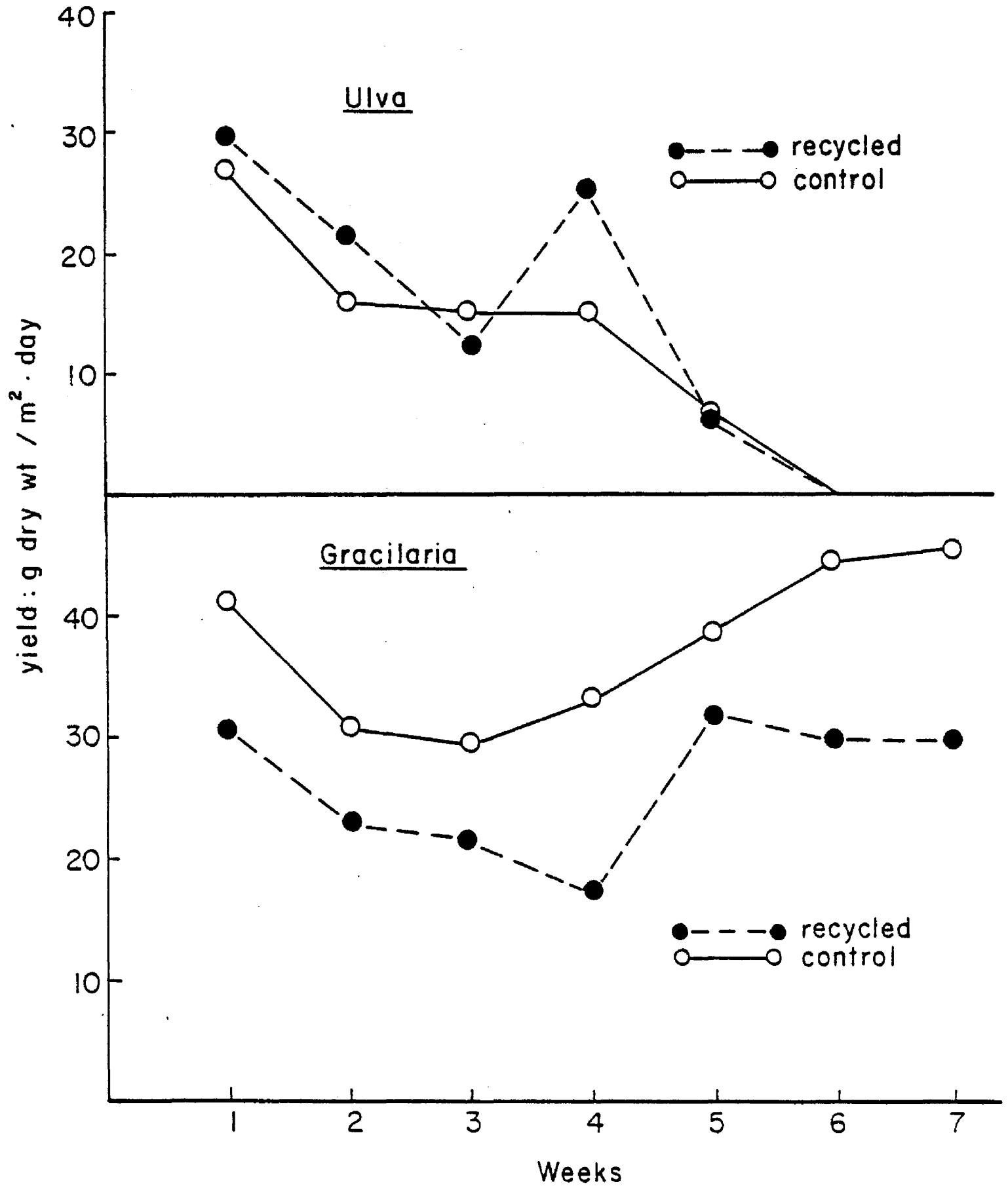

Figure 7 Growth of UTva and Gracilaria in mineral enrichment medium (control) and in the liquid residue from the digestion of the weekly harvest of the same culture (recycled). 


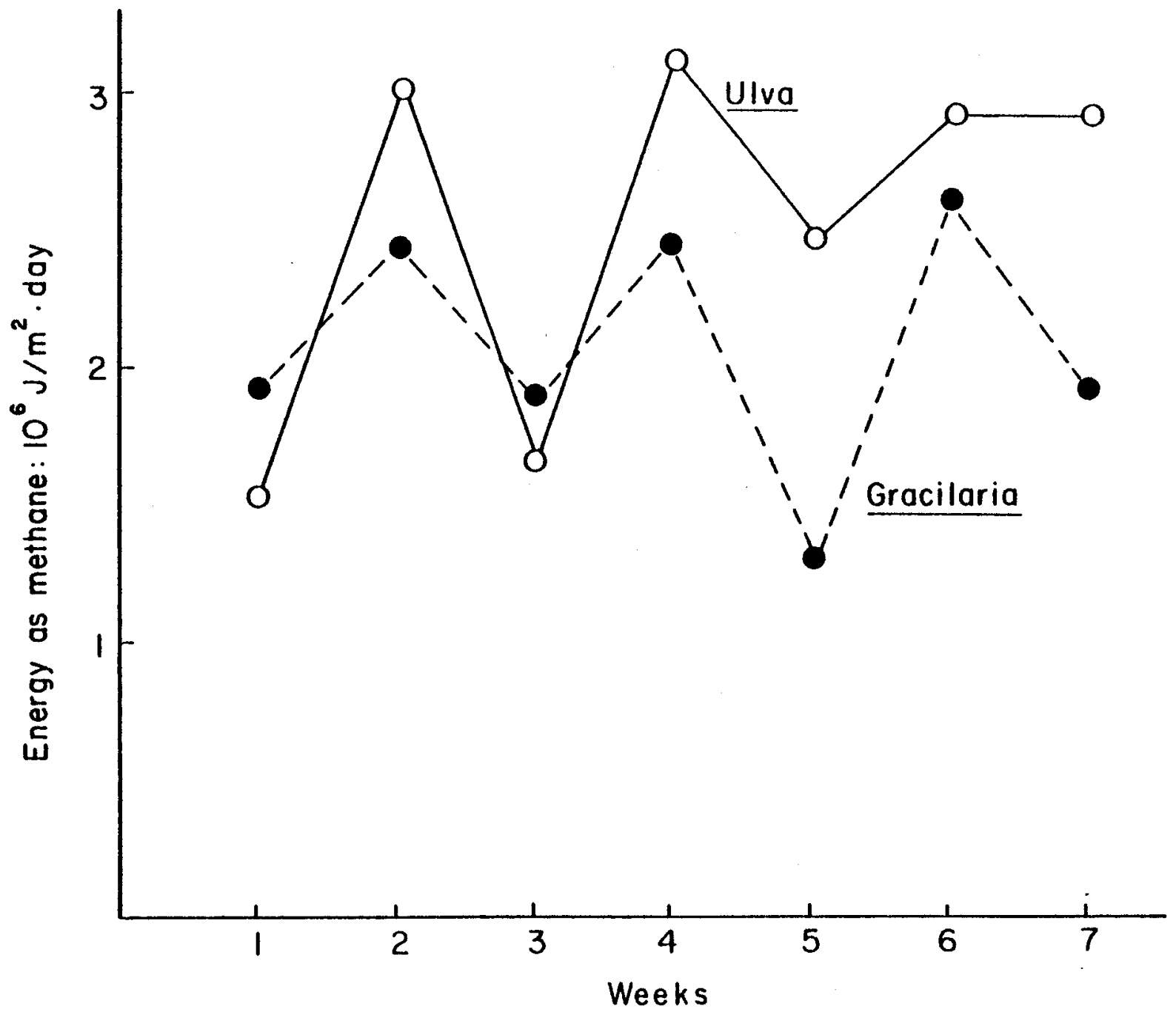

Figure 8 Energy yields as methane produced from the cultures grown in the recycled digester residues shown in Figure 7 . 
that Ulva is particularly promising as a marine biomass species for conversion to fuel, an advantage that will be complete if the present sterile population can be acclimated to the summer temperatures of Florida or if a new sterile clone indigenous to the area can be found, thereby permitting its yearround growth.

Conceptual model of a seaweed energy farm (adapted from Ryther and Hanisak, 1981):

Gracilaria or UTva may be grown loosely, on the bottom in shallow ponds or impoundments on land or in shallow coastal waters in tropical to semitropical latitudes such as may be found in the eastern Gulf of Mexico, off Florida, the Bahama Banks, or in parts of the Caribbean. At an offshore site, the seaweeds would presumably be confined by a fence or other barrier. Within the enclosure, it is maintained at a density of approximately $2 \mathrm{~kg}$ wet $\mathrm{wt} / \mathrm{m}^{2}$, at which it is compacted well enough that normal wind and tidal action will not move it and cause it to drift and accumulate unevenly.

Well nourished Gracilaria or Ulva exposed to full sunlight at such latitudes may be expected to double its biomass in one to four weeks depending upon season, water flow, and other variables discussed earlier. After its biomass has doubled (i.e., from 2 to $4 \mathrm{~kg} / \mathrm{m}^{2}$ ) the incremental growth should be harvested to return the crop to a starting density that will ensure continued optimal yield.

If the Gracilaria were well nourished, as stipulated, at the beginning of the growth period and were exposed to a normal tidal exchange or other flow of unenriched tropical or semitropical surface seawater during that period, the doubling of biomass would be accompanied by the utilization of all stored nutrients and a reduction of elemental nutrients in the plant tissues to roughly half the initial concentration (assuming essentially zero contribution from the seawater). 
Enrichment of the new starting crop following harvest (i.e., $2 \mathrm{~kg}$ wet $w t / \mathrm{m}^{2}$ ) could conceivably be accomplished on site in the seaweed farm, but the rapid uptake and storage of nutrients by depleted seaweeds, as illustrated earlier in this report, makes possible a simpler, more efficient enrichment process. This would involve harvest of the entire crop, half of which is permanently removed for utilization while the remaining half is exposed to a concentrated nutrient solution for the 6 -hour period that is needed for the plants to double their nutrient content.

The relatively small Gracilaria or Ulva plants, which seldom exceed a diameter of $20-30 \mathrm{~cm}$ per individual clump and which readily break up into smal1, individual plants with any agitation, would be readily harvested by pumping to a central processing, utilization, and enrichment plant located as close as possible to the farm site. A circular farm with the processing plant at its central hub would appear to be most efficient. Such a design would permit the farm to be subdivided into pie-shaped segments that could be routinely harvested at intervals of one to several days (depending upon the time required to carry out the complete operation), returning the enriched half of each harvest to the appropriate farm segment.

The remaining half of each harvest would be anaerobically digested. The residue from the digesters, with whatever additional processing as may be required to mineralize and/or otherwise make available the nutrients for assimilation and storage, would then serve as the enrichment medium for that portion of the harvest to be pumped back to the farm as the starting culture for the subsequent growth cycle.

The biogas generated from the anaerobic digestion of the seaweed may be piped ashore but would better be utilized on site as process energy for any appropriate local industry. The exhaust gas from the biogas combustion, primarily $\mathrm{CO}_{2}$, would then be available for distribution to the seaweed 
farm, the yield of which will otherwise be $\mathrm{CO}_{2}-1$ imited.

In the preceeding conceptual design, all materials are perpetually recycled. Nutrients, including $\mathrm{CO}_{2}$, needed as make-up for inefficiency in the recycling processes, are provided with the normal tidal and nontidal flow of seawater through the farm.

As an alternative to Gracilaria or Ulva for a biomass feed stock, a floating species of seaweed could be used in offshore situations where the water might be too deep or turbid (or both) to permit high growth rate of a benthic species or where the bottom is too soft, irregular, or otherwise unsuitable. The site might still be shallow enough for the fences or other boundaries of the farm and the processing plant to be fixed to the bottom, with only the seaweed itself suspended at the sea surface by its own buoyancy. Large areas of the eastern Gulf of Mexico, for example, are of a depth suitable for such systems (e.g., 10-20 m).

The floating species of Sargassum, $\underline{S}$. natans, and $\underline{S}$. fluitans that occur throughout the tropical to semitropical Atlantic as well as the Caribbean and Gulf of Mexico would be particularly suited for this purpose, the former especially so because it is known only as a sterile, vegetative plant. Little or nothing is known about the growth rates or potential organic yields of these familiar species of seaweeds, which otherwise would appear to be ideally suited for biomass farming in terms of their size, habit, distribution, and other features. Clearly, this is an area where basic physiological data are needed for those and perhaps for other, less common species of seaweeds that could be even more suitable for energy farming. Until such basic information is available, no realistic economic analysis or net energy balance of a biomass system based upon these species is possible, but the concept of their use for such a purpose, as described above, is attractive enough to justify the necessary research. 


\section{LITERATURE CITED}

Bender, E. 1980. Marine biomass research advances. Sea Tech. 1980:19-24. Blinks, L. R. 1963. The effect of pH upon the photosynthes is of littoral marine algae. Phycologia 57:126-136.

Chapman, A. R. O. and J. S. Craigie. 1977. Seasonal growth in Laminaria longicruris: Relations with dissolved inorganic nutrients and internal reserves of nitrogen. Maz. Biol. 40:197-205.

D'Elia, C. F. and J. A. DeBoer. 1978. Nutritional studies of two red algae. II. Kinetics of ammonium and nitrate uptake. J. Phycol. $14: 226-272$.

Dynatech R/D Co. 1978. Cost analys is of aquatic biomass systems. Rept. to the U.S. Dept. of Energy. HCP/ET-4000-78/1, July 25, 1978. 2 volumes. Goldman, J. G., M. R. Dennet and C. B. Riley. 1981. Inorganic carbon sources and biomass regulation in intensive microalgal cultures. Biotech. Bioeng. 25:995-1014.

Habig, C. and J. H. Ryther (in press) Methane production from the anaerobic digestion of some marine macrophytes. Res. and Cons.

Habig, C., T. A. DeBusk and J. H. Ryther (unpubl. ms.) The effect of nitrogen content on methane production by the marine algae Gracilaria tikvahiae and UTva sp. Submitted to Appl. and Env. Microbiol. Harvey, H. W. 1960. The chemistry and fertility of seawaters. The University Press, Cambridge. 240 pp. Huguenin, J.E. 1976. An examination of problems and potentials for future large-scale intensive seaweed culture systems. Aquaculture 9:313-342. Jolliffe (Thomas), E. A. and E. B. Tregunna. 1970. Studies on $\mathrm{HCO}_{3}$ - ion uptake during photosynthesis in benthic marine algae. Phycologia 9:293-303. 
Jones, J. L. 1979. The cost of methane from kelp grown in an open-ocean farm. Preprints Chem. Marketing and Econ. Div., Am. Chem. Soc. Mtg., Honolulu, Hawaii, April, 1979. 38 pp.

Littler, M. M. 1980. Morphological form and photosynthetic performances of marine macroalgae: Tests of a functional/form hypothesis. Bot. Mar. 22:161-165.

Neish, A. C., P. F. Shacklock, C. H. Fox and F. J. Simpson. 1977. The cultivation of Chondrus crispus: Factors affecting growth under greenhouse conditions. Can. J. Bot. 55:2263-2271.

Odum, E. P., E. J. Kuengler and M. X. Blunt. 1958. Uptake of $P^{32}$ and primary productivity in benthic marine algae. Limnol. Oceanog. 3:340-345. Osterlind, S. 1952. Inorganic carbon sources of green algae. VI. Further experiments concerning photoactivation of bicarbonate assimilation. Physiol. Plant. 5:403-408.

Rosenberg, G. and J. Ramus. 1982. Ecological growth strategies in the seaweeds Gracilaria fol iifera (Rhodophyceae) and Uiva sp. (Chlorophyceae): photosynthesis and antenna composition. Mar. Ecol. Prog. Ser. 8:233-241. Ryther, J. H., N. Corwin, T. A. DeBusk and L. D. Williams. 1981/82. Nitrogen uptake and storage by the red alga Gracilaria tikvahiae (McLachlan, 1979). Aquacuiture 26:107-115.

Ryther, J. H. and M. D. Hanisak. 1981. Anaerobic digestion and nutrient recycling of small benthic or floating seaweeds. Proc. Symp. Energy from Biomass and Wastes V. Inst. Gas. Tech. Jan., 1981. Lake Buena Vista, Florida. 109 pp. 
1. Continue the search and screening for a high-temperature tolerant, sterile clone of Ulva spp., including adaptation, selection, and induced mutation studies of laboratory cultures under controlled conditions.

2. Complete small-scale studies on optimal yields of Gracilaria and U1va with minimal aeration, water exchange, and/or $\mathrm{CO}_{2}$ addition.

3. Complete nutrient recycling studies using digester residues with Gracilaria and Ulva, including characterization of residues as a function of digester residence time.

4. Continue spray culture studies with Gracilaria, Ulva, and other seaweeds, including intertidal species.

5. Pilot testing of recycling culture system in large $\left(7000 \mathrm{gal} ., 30 \mathrm{~m}^{2}\right)$ aluminum tanks with Gracilaria, using the following three culture modes simultaneously:
a. 10 seawater exchanges/day, recycled nutrients, no $\mathrm{CO}_{2}$ addition.
b. 1 seawater exchange/day, recycled nutrients, no $\mathrm{CO}_{2}$ addition.
c. I seawater exchange/day, recycled nutrients, and $\mathrm{CO}_{2}$.

6. Repeat (5) with high-temperature clone of UTva.

7. Pilot-testing of spray culture system using Gracilaria, Ulva, or other successful intertidal seaweed species.

8. Economic and energy balance analyses of (5), (6), and (7).

9. Bioassay of subterranean desert saline water for growth of Gracilaria, Ulva and other seaweed species.

10. Screening of Gracilaria, Ulva, and other rapidly growing macroalgae for compounds useful as fuels, fuel precursors (other than methane), or fuel-sparing compounds, in collaboration with Dr. T. G. Tornabene, Georgia Institute of Technology. 


\begin{tabular}{|c|c|c|c|}
\hline $\begin{array}{l}\text { Document Control } \\
\text { Page }\end{array}$ & $\begin{array}{l}\text { 1. SERI Report No. } \\
\text { SERI/STR-23I-1820 }\end{array}$ & 2. NTIS Accession No. & 3. Recipient's Accession No. \\
\hline \multirow{2}{*}{\multicolumn{3}{|c|}{ Cultivation of Macroscopic Marine Algae }} & $\begin{array}{l}\text { 5. Publication Date } \\
\text { November } 1982\end{array}$ \\
\hline & & & 6. \\
\hline \multicolumn{3}{|c|}{$\begin{array}{l}\text { 7. Author(s) } \\
\text { John H. Ryther }\end{array}$} & 8. Performing Organization Rept. No \\
\hline \multirow{2}{*}{\multicolumn{3}{|c|}{$\begin{array}{l}\text { 9. Performing Organization Name and Address } \\
\text { John H. Ryther } \\
\text { University of Florida }\end{array}$}} & 10. Project/Task/Work Unit No. \\
\hline & & & $\begin{array}{l}\text { 11. Contract (C) or Grant (G) No. } \\
\text { (C) XR-9-8133-1 } \\
\text { (G) }\end{array}$ \\
\hline \multirow{2}{*}{\multicolumn{3}{|c|}{$\begin{array}{l}\text { 12. Sponsoring Organization Name and Address } \\
\text { Solar Energy Research Institute } \\
1617 \text { Cole Boulevard } \\
\text { Golden, Colorado } 80401\end{array}$}} & $\begin{array}{l}\text { 13. Type of Report \& Period Covered } \\
\text { Technical Report }\end{array}$ \\
\hline & & & 14. \\
\hline
\end{tabular}

16. Abstract (Limit: 200 words) The red alga Gracilaria tikvahiae may be grown outdoors yearround in central Florida with yie Tds averaging $35.5 \mathrm{~g}$ dry wt $/ \mathrm{m}^{2}$ - day, greater than the most productive terrestrial plants. This occurs only when the plants are in a suspended culture, with vigorous aeration and an exchange of 25 or more culture volumes of enriched seawater per day, which is not cost-effective. We tried to retain high yields at less energy and economic cost. We designed a culture system in which Gracilaria, stocked at a density of $2 \mathrm{~kg}$ wet $\mathrm{wt} / \mathrm{m}^{2}$, grows to double its biomass in one to two weeks; it is then harvested to its starting density, and anaerobically digested to methane. The biomass is soaked for 6 hours in the digester residue, storing enough nutrients for two weeks' growth in unenriched seawater. The methane is combusted for energy and the waste gas is fed to the culture to provide mixing and $\mathrm{CO}_{2}$, eliminating the need for aeration and seawater excharige. The green alga Ulva lactaca, unlike Gracilaria, uses bicarbonate as a photosynthesis carbon source, and can grow at high $\mathrm{pH}$, with little or no free $\mathrm{CO}_{2}$. It can therefore produce higher yields than Gracilaria in low water exchange conditions. It is also more efficiently converted to methane than is Gracilaria, but cannot tolerate Florida's summer temperatures so cannot be grown year-round. Attempts are being made to locate or produce a high-temperature tolerant strain.

17. Document Anatysis

a. Descriprors Biomass plantations; Growth; Plant growth; Seawater; Seaweeds;

Stimulation

b. Identifiers/Open-Ended Terms

c. UC Categories

$67 \mathrm{a}$

18. Availabiiity Statement

National Technical Information Center

U.S. Department of Commerce

5285 Port Royal Road

Springfield Virginia 2216]

19. No. of Pages

35

20. Price

$\$ 4.50$ 